\title{
THE USE OF A METEOROLOGICAL STATION NETWORK TO PROVIDE CROP WATER REQUIREMENT INFORMATION FOR IRRIGATION MANAGEMENT
}

\author{
Reimar Carlesso ${ }^{1, *}$, Mirta Teresinha Petry ${ }^{2}$, Celio Trois ${ }^{3}$ \\ ${ }^{1}$ Professor of the Agriculture Engineering Department, Federal University of Santa Maria, \\ RS, Brazil.97105-900.E-mail: reimar.carlesso@gmail.com \\ ${ }^{2}$ Federal University of Santa Maria, RS, Brazil.97105-900.E-mail: mirta.petry@gmail.com \\ ${ }^{3}$ Professor of the Federal Technical Institute, São Vicente do Sul, RS, Brazil.E-mail: trois@ \\ gmail.com \\ * Corresponding author, Address: Department of Agricultura Engineering, Federal University \\ of Santa Maria, DER-CCR, Campus Camobi, 97119-900, Santa Maria-RS, Brazil, Tel: \\ +55-55-99714994, Fax:+55-55-32208399,Email:reimar.carlesso@gmail.com
}

Abstract: Despite of the water use increment for other sectors than agriculture, the water use for irrigation is the main water consumer in global scale. However, irrigation has been pressured by the civil society to improve water use efficiency in agriculture, to prevent water scarcity for human population that grows continuously, mainly in developing areas of the planet. On the other hand, the irrigation practice is considered the main tool to increase water use efficiency, either for increasing crop production or for keeping rural works in the agricultural areas. The water use efficiency can be improved through the adoption of an efficient irrigation management and programming that results in water conservation. Several methods of irrigation management have been developed and used in the last few decades, but the adoption of the majority of then by the irrigated grower was limited by the cost, time of installation, maintenance and local difficulties that the selection of a specific method involves. In arid regions, the decision of "when" and "how much" to irrigate is relatively simple. However, in wet regions when complementary irrigation is used, the irrigation scheduling is a complex task, mainly due to the water added from rainfall events. The Sistema Irriga ${ }^{\mathrm{TM}}$ is basically a service of irrigation management developed by the Federal University of Santa Maria, Brazil. The criteria used by this method to decide the amount of each irrigation application is based on crop parameters of the irrigated crop, soil physical characteristics, meteorological conditions and characteristics of the irrigation

Please use the following format when citing this chapter:

Carlesso, R., Petry, M.T. and Trois, C., 2009, in IFIP International Federation for Information Processing, Volume 293, Computer and Computing Technologies in Agriculture II, Volume 1, eds. D. Li, Z. Chunjiang, (Boston: Springer), pp. 19-27. 
system and irrigation method, combined with a mathematical model to determine the reference and crop evapotranspiration. This paper describes all factors and parameters used by the Sistema Irriga ${ }^{\mathrm{TM}}$ service, since the data acquisition (plant, soil, weather and irrigation system information), data processing and how the irrigation recommendation is available to the farmers.

Keywords: Weather station, reference evapotranspiration, irrigation management. Introduction

\section{INTRODUCTION}

Recent studies published by FAO (2002) showed some alterations in the world food production panorama, comparing to previous estimates. According to Food and Agricultural Organization (FAO), there is an increase in food production, besides the tendency to decrease demographic rates, resulting in a reduction of agricultural use of the natural resources. The increase in agriculture productivity is the most important reason for increasing the world production. Developed countries increased $70 \%$ their food production mainly due to the incorporation of new technologies in cropping systems and management practices, especially irrigation.

The FAO has estimate that the irrigated area will be around 300 million hectares in 2030. This statistic will add great pressure to improve irrigation water management, since the agricultural are responsible for $70 \%$ of fresh water consumption.

Many technologies can be used by farmers to combine yield increasing with environmental protection, such as conservation tillage systems, using integrate pest and disease management and the best use of biotechnology. However, the improvement of water use efficiency in agricultural crop system will only be possible with the adoption of an adequate irrigation management system, to avoid waste of water and reduction in production due to excessive or under irrigation. According to Howell (2000), without a proper irrigation management, irrigated agriculture may undermine the sustainability of the system.

The technology present in many areas is very high, including meteorology and agriculture, making possible the automatic tracking of several meteorological variables in real time. Not only meteorological data can be automatically acquired, but also other data related to agriculture are being monitored specially related to plant and soil.

One of the main applications of real time meteorological data in agriculture is to estimate the reference evapotranspiration (ETo). It is possible to build a network with several automatic weather stations (AWS), which increase the quality of collect meteorological data. Combining these 
variables with an adequate irrigation management system will improve the water use in agriculture.

In South America, specifically in Brazil, the use of AWS is recent; and a large number is installed in research institutes, however, the use of AWS by farmers has been increasing continuously. Based on meteorological data collected from a particular region, soil, plant and equipment information, it is possible to recommend when is necessary to irrigate and how much water the farmer should apply on a specific irrigated area. The irrigation recommendation is available to users by phone or through Sistema Irriga ${ }^{\mathrm{TM}}$ 's web page - www.sistemairriga.com.br.

The main objective of this paper is to describe the Sistema Irriga ${ }^{\mathrm{TM}}$ criteria for irrigation management, especially the data collection, transmission and calibration of the used AWS network, as well as the ETo and Etc determination and the irrigation scheduling information distributed to the farmers through the internet.

\section{SYSTEM DESCRIPTION - DEVELOPMENT}

\subsection{Automatic weather station location}

The AWS network is used to satisfy several needs, ranging from a simple aid-to-the-observer to fully automatic stations that provide information to weather forecast, aeronautical and agricultural meteorology. When the purpose is to estimate the ETo for dissemination of irrigation crop requirements, the AWS location follows the same rules established by de World Meteorological Organization (WMO) for the conventional stations. Generally, the AWS's are fully accepted as meteorological stations when providing data with comparable accuracy as the ones collected from conventional stations. The AWS's have several advantages over conventional stations. In general, due to its characteristics of mobility, they can be installed in isolated areas, without electric energy supply, for instance.

The Agricultural Engineering Department of the Federal University of Santa Maria (UFSM), Rio Grande do Sul, Brazil, had implemented a network of AWS. Nowadays, this network has a total of 86 AWS distributes in several Brazilian States and in Uruguay (Figure 1). The data measured by AWS are collected and sent directly through internet, phone, satellite, etc. to a datacenter to be processed and stored. 


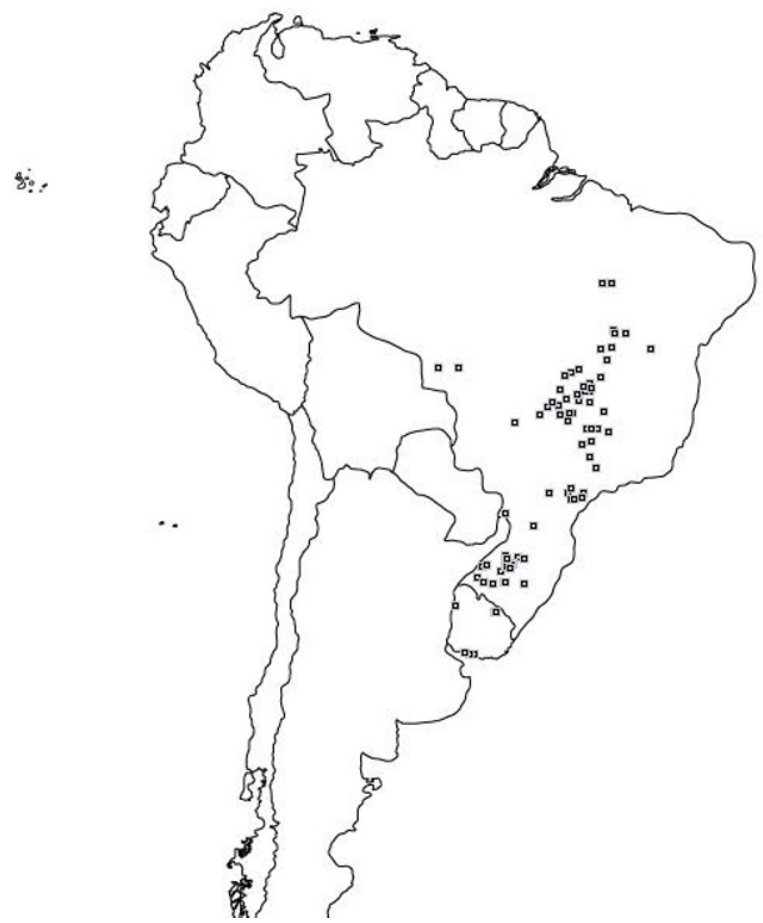

Fig.1: Distribution of the automatic weather station network used by the Sistema Irriga to provide irrigation management information to farmer in Brazil and Uruguay

A mathematical model is used to process the meteorological data and estimate ETo and ETc and together with crop growth, soil characteristics and irrigation system information to determined the irrigation scheduling. Furthermore, the Sistema Irriga ${ }^{\mathrm{TM}}$ has a service that also indicates to the farmers when $\mathrm{N}$ fertilization has to be applied based on crop phenology.

The AWS network is distributed on major irrigated areas in Brazil. Generally, each AWS is positioned to provide information to the largest possible area, reducing acquisition, transmission and maintenance costs. The distance between the AWSs is around 50 to $70 \mathrm{~km}$, since the altitude does not varies more than $200 \mathrm{~m}$. The network is constantly upgraded by adding a new AWS, aimed to collect data in remote and isolated areas and improve the quality and precision of information provided by the Sistema Irriga ${ }^{\mathrm{TM}}$.

\subsection{Data collection and transmission}

The online collection presents a lot of advantages in relation to manual collection, because it does not need a person intervention. The most common forms to make the online collection is to interfacing the equipment to a CPU using available serial or USB ports. Once connected to a CPU, measured data can be read by specific software. Collected data can be stored in a local 
unit (CPU) or sent to a datacenter. Data are normally transmitted to a datacenter through an internet connection (dial up connection, ADSL, cellular, satellite links, etc.). Each transmission technology has its benefits and cost. Nowadays, the internet connection using a cellular modem represents a low cost. On the other hand, satellite connections can also be used, including very remote sites, but the main problem is the high cost for implementation and maintenance. The AWS network of the Sistema Irriga ${ }^{\circledR}$ uses different data transmission systems on each irrigated region, to avoid problems on data reception and availability.

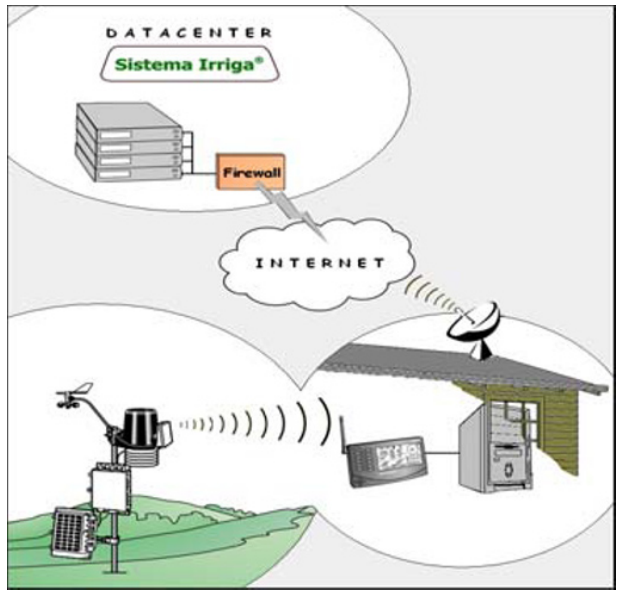

Fig. 2: Data collection and transmission from an automatic weather station to the datacenter of the Sistema Irriga ${ }^{\mathrm{TM}}$.

On table 1 is presented the data range, sensor resolution and accuracy of the meteorological data collected and processed from each AWS of the network.

Table 1: Details of the accuracy, specific measurements range of the automatic weather station network of the Sistema Irriga ${ }^{\mathrm{TM}}$.

\begin{tabular}{llcc}
\hline Sensor & Range & Accuracy & Unit \\
\hline Air Pressure & 750 a 1060 & 0.3 & $\mathrm{hPa}$ \\
Air temperature & -25 a +60 & 0.3 & ${ }^{\circ} \mathrm{C}$ \\
Relative Humidity & 2 a 100 & 3 & $\%$ \\
Wind Speed & 1.03 a 92.6 & 2 & $\mathrm{~m} / \mathrm{s}$ \\
Wind Direction & 0 a 359 & 5 & degree \\
Rainfall & 0 a 999.8 & $2 \%$ & $\mathrm{~mm}$ \\
Solar radiation & 0 a 1500 & 5 & $\mathrm{~W} \mathrm{~m}-2$ \\
\hline
\end{tabular}

Soon after receiving the data, the server automatically runs a filter to verify if the data are inside the specified range (Table 1). In case of inconsistency they are only stored but not used for irrigation purposes. 
Currently, two SGI servers, dual-core Xeon 2 Gb of memory RAM and 2 HDs of $250 \mathrm{~Gb}$. Also, an off-site server DELL is used as backup. All the servers use Linux OpenSource 10.2. The data base is MySQL 5.0 supporting a $2.4 \mathrm{~Gb}$ database of information stored since 2002 .

The servers process automatically more than 500 algorithms with information of the weather conditions, crop growth and development, soil physical characteristics, crop management system and characteristics of the irrigation system. All information is process by PHP and Javascript languages using version 5.1.6 of the PHP and Apache 2.2.

The maintenance and calibration of each sensor of AWS is a constant task. Calibration is made by specific companies of Technical Assistance. The maintenance is conducted every two years and consists of sensor reconfiguration (in the case of replacement), communication test, adjustment, cleaning, etc.

\subsection{Basic parameters used by the Sistema Irriga ${ }^{\mathrm{TM}}$}

\subsubsection{Soil parameters}

Some soil physical characteristics are fundamental for irrigation management, such as: soil water holding capacity, soil plant availability, soil infiltration, soil structure, texture, bulk density and soil porosity. In each irrigated area, soil samples are collect in trenches of approximately $80 \mathrm{~cm}$ length, $60 \mathrm{~cm}$ width and $75 \mathrm{~cm}$ depth. The soil profile is usually divided in three layers: superficial, intermediate and inferior. Each trench represents approximately an area of 50 hectares. Undisturbed soil samples are collected using rings of $50 \mathrm{~mm}$ in diameter and $25 \mathrm{~mm}$ height.

\subsubsection{Crop parameters}

Crop characteristics such as leaf area, height, root depth and distribution, plant population, canopy architecture, row space, etc. are important to determine ETc. Several field experiments have been conducted to validated crop parameters for different varieties, hybrids and cultivars. Currently, the data base of the Sistema Irriga ${ }^{\mathrm{TM}}$ has validated data of leaf area index, plant height, crop growth and development (cumulative thermal time) for the following crops: pumpkin, alfalfa, garlic, rice, cotton, potato, brachiaria, onion, carrot, barley, coffee, pea, beans, sunflower, apple, maize, sweet corn, popcorn, peach, pear, soybean, sorghum, tobacco, tomato, wheat and grapevine. 


\subsubsection{Irrigation system parameters}

The irrigation system information, such as: minimum and maximum irrigation depth, distribution uniformity coefficient, irrigation efficiency among others, is used to determine the frequency and irrigation duration. Figures 3 presents a simplified layout of the system operation, with the basic four factors considered in each irrigation recommendation and the different ways the information reached the farmers.

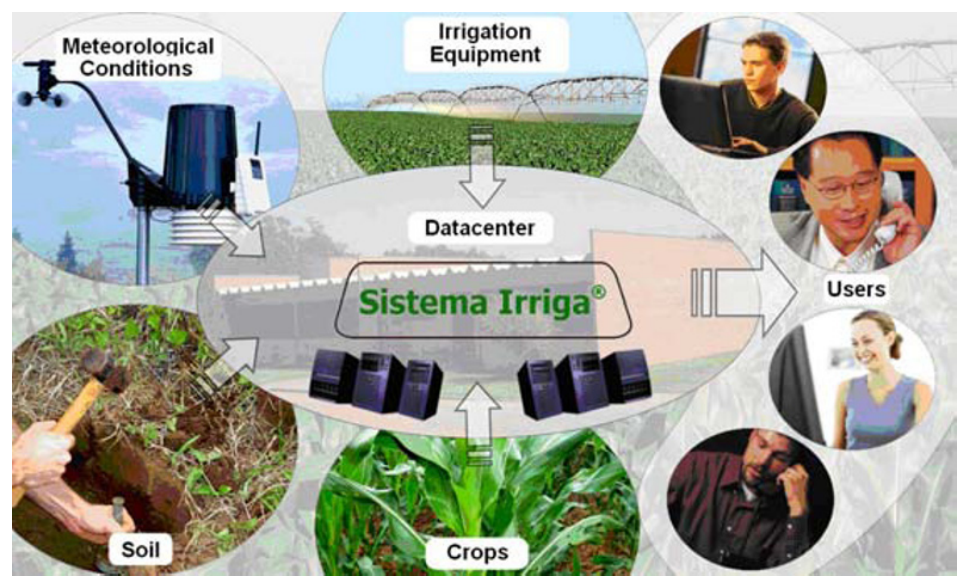

Fig. 3: Simplified layout of the Sistema Irriga ${ }^{\mathrm{TM}}$ operation.

\subsection{Reference and crop evapotranspiration determination}

The ETo depends basically on meteorological data. Consequently, the ETo is a climatic parameter and can be estimated based on meteorological data. The method of Penman-Monteith described in FAO-56 (Allen et al., 1998) is used to determine ETo and ETc. Initially the values of crop coefficient $(\mathrm{Kc})$ used by the Sistema Irriga ${ }^{\mathrm{TM}}$ are the ones suggested for Allen et al. (1998). Constantly adjustments and/or corrections of the original Kc values are carried out in the field, generating a new set of coefficients, as a function of the different crop cultivation system, soil management, varieties, cultivars or hybrids, etc. (field experiments constantly are installed in different regions of Brazil for adjustments of the crop growth and development). 


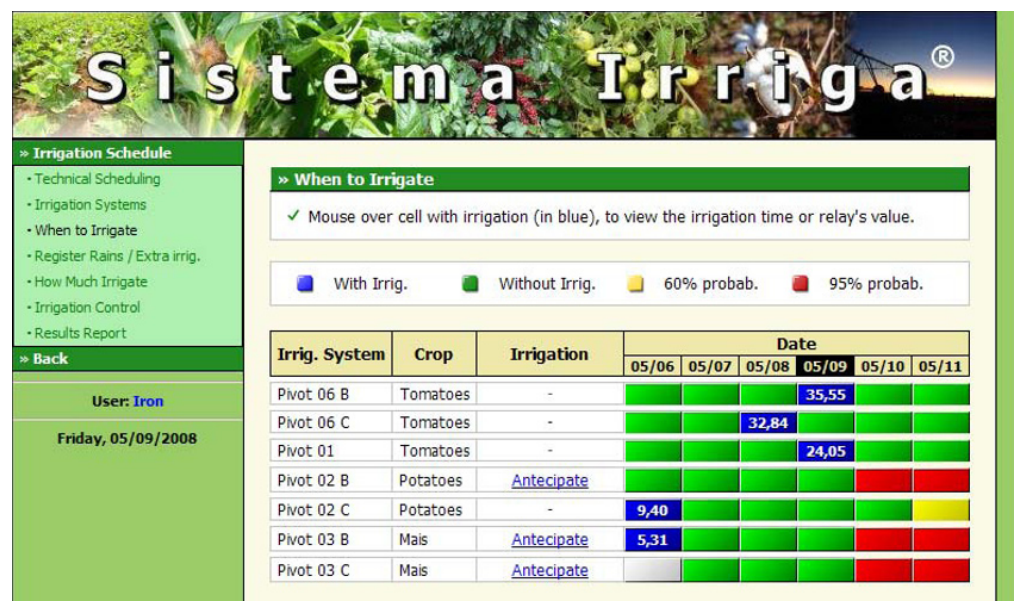

Fig.4: Main web page of Sistema Irriga ${ }^{\mathrm{TM}}$ showing daily when to irrigate and how much water to apply for each crop and irrigation system.

\subsection{Irrigation scheduling}

The irrigation scheduling provided by the Sistema Irriga ${ }^{\mathrm{TM}}$ easily indicates when to irrigate and how much water to apply in each irrigation. Irrigated farmers have daily to access the web page of the system (www.sistemairriga.com.br). The daily recommendation of when and how much to irrigate is based on the basic four parameters described earlier (weather, plant, soil and irrigation equipment). Besides the daily recommendation the system provide an irrigation forecast for the next 24 and 48 hours (Figure 4).

\section{FINAL CONSIDERATIONS}

The Sistema Irriga ${ }^{\mathrm{TM}}$ initiated as a pilot project in 1999, using only one AWS to manage 540 hectares. In 2000 and 2001, using three AWS, 2500 hectares were monitored in Southern Brazil, increasing to 10.000 ha in 2002 (using 14 AWS). The annual evolution of the monitored irrigated areas and number of farmers that uses the system is presented in fig. 5. Nowadays, more than 185,000 hectares have been monitored since the creation of the system. 


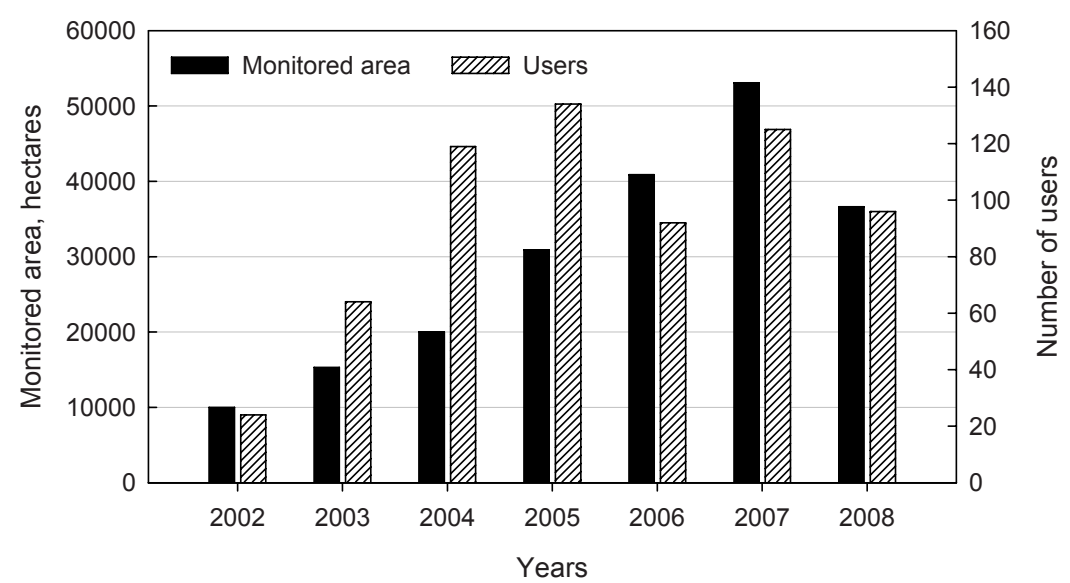

Fig.5: Annual evolution of the monitored irrigated areas and number of farmers that uses the system from 2002 to 2008 .

\section{REFERENCES}

EMBRAPA. Manual de métodos de análises de solo. 2 ed. Rio de Janeiro: Ministério da Agricultura e do Abastecimento, 1997, $212 \mathrm{p}$.

R.G. Allen, L.S. Pereira, D. Raes, M. Smith. Crop evapotranspiration. guidlines for computing crop water requirements. FAO Irrigation and Drainage Paper 56, FAO, Rome, Italy, $1998,300 \mathrm{p}$.

T.A. Howell. Irrigation role in enhancing water use efficiency. In: National Irrigation Symposium. American Society fs Agricultural Engineers, Phoenix, Arizona, 2000, p.66-80. 